\title{
Development of Three Dimensional Based Learning Media Barcode for Basic School
}

\author{
Ria Triayomi ${ }^{1}$, Theresia Widyastuti ${ }^{2}$ \\ \{riatriayomi@ukmc.ac.id\} \\ Department Of Teacher School Education Teacher, Catholic Musi Charitas University,Jalan Bangau \\ No.60 Palembang 30113, Indonesia ${ }^{1}$,Department Of Psychology, Catholic Musi Charitas University, \\ Jalan Bangau No.60 Palembang 30113, Indonesia ${ }^{2}$
}

\begin{abstract}
This research aims to produce a valid and practical barcode-based threedimensional learning media for primary schools and has an effect on learning outcomes in learning Science. The module based on the website was developed through three stages, namely needs analysis, design/planning stage, development, and implementation stage. To view its validity had evaluated by experts, to look at its practicalities had used one-on-one evaluation and small groups' evaluation, while to look at the effective had used field test and student's activity. The results showed that the evaluation of exports amounted to 4.27 with very valid criteria, the results of questionnaires student response data showed an average of $76 \%$. Learning outcomes with score gain score of 0.78 with the high category. Students' activity is $85.4 \%$ with very good criteria. The development of three-dimensional based learning media developed has been valid, practical, and affects student learning outcomes and activeness.
\end{abstract}

Keywords: Three Dimensional Learning Media, Barcode Based, Elementary School

\section{Introduction}

The implementation of the 2013 curriculum is one way to improve the quality of Indonesian education. The curriculum becomes important in line with the continuity of the progress of science, technology, and arts and culture as well as changes in society at the local, national, regional and global levels in the future. The 2013 curriculum applies technology as a supporting tool in the learning process. In each subject integrated with technology [1]. Information and communication technology, especially the use of computers and gadgets, is currently growing rapidly. One of them is the application of multimedia. Multimedia has changed the way humans interact. Multimedia applications can quickly attract someone's attention, they can be utilized according to their individual needs. Not only in the world of entertainment but multimedia is also used in education in the learning process. The 2013 curriculum applies information and communication technology (ICT) as a supporting tool for all subjects.

Curriculum Development in 2013 aims to encourage students or students so that they are better able to make observations, ask questions, reason, and communicate, what is obtained or 
known after students learn the learning material. The theme for developing the 2013 curriculum is to produce Indonesian people who are productive, creative, innovative and effective through the strengthening of integrated attitudes, skills, and knowledge. The core of the 2013 curriculum is a simplification and thematic-integrative effort.

Also, the 2013 curriculum has several characteristics as written in Minister of Education and Culture Regulation Number 67 of 2013 [2] Regarding the Basic Framework and Structure of the Elementary School / Madrasah Ibtidaiyah Curriculum. Characteristics of the 2013 curriculum is a curriculum that develops a balance between developing spiritual and social attitudes, curiosity, creativity, collaboration with intellectual and psychomotor abilities.

Another characteristic highlighted by the 2013 curriculum is that the curriculum reinforces the essence of schools as part of a community that provides planned learning experiences. Students are trained to apply what is learned in school to the community and utilize the community as a source of learning so that learning becomes meaningful.

Learning is carried out in a thematically integrated with the aim that students can develop themselves and their competencies holistically and meaningfully. Thematic learning is an approach to learning that intentionally links several aspects both within intra subjects and between subjects. With the integration, students will gain knowledge and skills in full so that learning becomes meaningful for students (Ministry of National Education, 2014). This means that thematic learning that is carried out according to the 2013 curriculum is learning with certain themes that relate not only intra and between subjects but also the integration of learning between classes.

Based on the description above, one of the findings in the field is that the learning media used by teachers do not meet the times. The data obtained that every elementary school student has been able to use smartphone technology and the learner's handbook has been barcode-based. Therefore, researchers will develop a multimedia barcode-based learning media for elementary schools. So that the material can be obtained by students in a variety of ways according to the way children learn. Based on the above background, the formulation of this study is how to produce a three-dimensional encoded multimedia learning media for primary schools that is valid, practical and effective on learning outcomes.

Based on the background and the formulation of the problem, the purpose of the study is to produce a multimedia barcode-based learning media for primary schools that is valid, practical, effective in terms of student learning outcomes and activeness. The research is expected to provide benefits including (1) for students, this learning media can improve learning outcomes of elementary school students; (2) for teachers, can provide innovative learning media learning activities, so that learning is more directed; (3) for schools, the availability of learning media following the valid times; (4) for other researchers, this research can be an additional reference as one of the provisions for conducting a three-dimensional encoded multimedia learning media research for elementary schools.

\section{Experimental Method}

Development research (development research) using the Hannafin and Peck development models. According to [3] Hannafin and Peck's development model consists of 3 stages of development, namely: (1) needs analysis; (2) design/planning; and (3) development and implementation. Next to formative evaluation researchers use Tessmer. There are five stages 
of the evaluation carried out, namely: (1) Self Evaluation; (2) Experts Review; (3) one to one evaluation; (4) small group; (5) field test.

The selection of this model is based on the consideration that this model was systematically developed by researchers and rests on the theoretical foundation of productoriented learning design. At each stage of development, Hannafin and Peck are revised and evaluated, so the researcher modifies with a self-evaluation evaluation contained in Tessmer's formative evaluation. Hannafin and Peck's development model in each stage of development there is evaluations and revisions. Evaluations and revisions made by researchers themselves to reduce errors during development. Hannafin's and Peck's development models are limited to self-evaluation. So researchers modified Hannafin and Peck's development models with Tessmer's formative evaluation [4].

The location of the study is SD Palembang Xavier 2 Palembang. In this study, the subject of the study was class VI of the odd semester of the 2019/2020 school year. Threedimensional multimedia learning media encoded for elementary schools will be used by students to become alternative learning media.

Development of coded three-dimensional multimedia learning media for elementary schools with several stages of activities listed at the development stage. The following stages of the Hannafin and Peck model are as follows: 1) the needs analysis phase, identifying the needs in developing a media including the goals and objectives of development. Also, identify the knowledge and skills of students who will use mobile phones. The analysis was conducted by researchers by reviewing journals and articles about barcode-based learning media that can help students in the learning process and interviews with teachers to find out the problems that occur.

Gather information to develop the objective of developing barcode-based learning media. Determine the software and hardware to be developed. Every step carried out in this stage is evaluated and revised according to literature and expert studies; 2) the design/planning stage, at this stage the information from the requirements analysis stage is transferred into a document that will be the purpose of making the product. Aiming to identify and document the best rules for achieving the goal of making the module Hannafin and Peck stated that the design phase aims to create a design. The design was made after identifying the needs and setting learning objectives in the preparation of lesson plans.

Basic competence and indicators of achievement of competence that explains the theme 1 save living creatures and sub-theme 1 of my best friend's plants. This stage is subsequently evaluated and revised based on a literature review Flowchart was also created during this stage. The flowchart will display the application flow while the storyboard is an example of the learning sequence and interface layout that will be provided to the user. The layout also includes multimedia elements that are designs that are appropriate to the learning process. Three-dimensional learning media developed by developing local culture show Palembang culture, which consists of Jperpa Ampera, Pagoda Building, Monpera Building, Palembang traditional house building, Limas. with dimensions of $50 \times 70 \mathrm{~cm}$. The website address is qr.crayonmedia.id .; 3) the development and implementation stage, the researcher makes a flow chart income, testing, and formative assessment.

The results of the development to find out its effect on the quality of learning which include validity, effectiveness, and effectiveness of learning. To ensure application development is carried out correctly, One important step in this development stage is validation with experts. The process to see whether the barcode-based learning media developed by researchers succeeded following expectations or not, researchers conducted formative evaluations. 
Formative evaluation stage [4], namely: 1) self-evaluation, at this stage overcoming errors when developing research, consisting of analysis and design conducted by researchers. At this stage, it is carried out during the requirements analysis and design stages; 2) expert review, the results of designs developed by researchers are given to experts (experts) to be validated. Validation is a measure that states the validity of an instrument so that it can measure what is being measured. Test the validity of the instruments used are the validity test of the material, learning design and media validity [5]. Suggestions for comments given to expert reviews were then corrected by researchers in barcode-based learning media; 3) Test one by one, carried out tests on class VI students consisting of 3 people who have high, medium, and low abilities. One to one test is carried out to determine the practicality. Researchers conduct unstructured and open interviews then students are invited to provide comments/criticisms, suggestions or input on barcode-based learning media products that they have operated. This is to identify and reduce errors in the barcode-based learning media so that the products produced can be easily used by students.

The results of the questionnaire, suggestions, and comments at this stage will be used as a basis for improving the barcode-based learning media developed by researchers. After the product being developed is repaired then it will carry out a limited trial; 4) Small group trials, conducted with 8 grade VI students. These students have the same characteristics as the characteristics of the students who were targeted by the study. At the end of the learning in small groups given a questionnaire, also, researchers were assisted by observers who will document the activities and record how students do the learning process by using barcodebased learning media developed by researchers

After learning is finished the researcher distributes the test to see the learning outcomes of students and is given a questionnaire and asks students to fill it in to get information about; (a) whether the learning activities are interesting and systematic; (b) which parts of the material in the learning multimedia are difficult to understand and for what reasons; (c) whether the questions and instructions are clear enough; (d) which test items are not relevant to the material presented; and (e) whether it is relevant between the learning objectives and the material contained in the learning media; (4) holding discussions with students to get more detailed information if possible; (5) analyze the data collected as feedback to revise the learning media product.

The results of the questionnaire, suggestions, and comments at this stage are intended to improve and perfect the barcode-based learning media developed by researchers to be more effective. After the product being developed is repaired the next stage is carrying out a field trial; 5) Field trials aim to find out the effectiveness of website-based modules on learning outcomes and student activity. The class used for the field test is the class that is the target of the study. Field test implementation starts with a pre-test and ends with a post-test. Products that have been tested on field tests must meet quality criteria. According to (Tessmer, 1998, p. 20) several focus questions need to be used as a benchmark in-field testing, including (1) ability to be implemented; (2) sustainability; (3) effectiveness; (4) compatibility with the environment; (4) acceptance and attractiveness.

According to [5] argues that there are three quality criteria: validity, practicality, and effectiveness. The effectiveness to be measured in this field test is a barcode-based learning media on the results. If the results obtained have reached at least $70 \%$ of the KKM value (75), then it is stated that the barcode-based learning media can already be appropriately utilized by students for the learning process.

The research data collection technique was conducted by researchers through data walkthroughs, interviews, questionnaires, observations, documentation, and learning 
achievement tests. The walkthrough is carried out at the expert review stage, used to determine the validity of barcode-based learning media. Interviews were conducted on the needs analysis and evaluation activities. In the needs analysis activities conducted interviews to explore the information needed in the formulation of the problem. In the interview, evaluation activities carried out to dig up information at one to one stage that aims to find out the weaknesses and shortcomings of the barcode-based learning media developed.

The questionnaire in the small group stage evaluation activity aims to obtain information in the form of comments and suggestions from students. Observation is used in the evaluation activities of small group stages and field tests. Assessment of student activities during the learning process to find out practicality. The learning achievement test is used during the field test evaluation activities

\section{Result and Discussion}

In the needs analysis phase, it is obtained that the learning media used by teachers do not meet the times. The data obtained that every elementary school student has been able to use smartphone technology and the learner's handbook has been barcode-based. Based on these results it is said that required learning media that meet the times such as barcode-based multimedia three-dimensional learning media, learning media will support an effective learning process. Besides this learning media also supports understanding the material through handbooks owned by students. If referring to the handbook that is currently circulating, there are printing companies that have used barcode bases. At this stage, self-evaluation and literature review are carried out in the form of books, journals. The results of the selfevaluation are prototype 1 . After all the needs have been identified the next step is to the design and planning stages.

In the next stage, it produces flowcharts, three-dimensional learning media, and software that are used as well as lesson plans as a guide for implementing learning. The revision was carried out by improving the lesson plans and flowcharts. In the flowchart that was made, there was an error in making flowchart symbols adjusted to the literature review about making a flowchart of learning media development.

This product is developed by two stages, namely making three-dimensional media and software that will be used on barcodes. Software that is used by Content Management System (CMS) is a tool or combination of tools that are efficient, effective, and easy to create web pages using a content management system (Asepnurdin, 2014). The reason for using open source CMS, this CMS was created and developed by a group of people who provide an inexpensive and affordable alternative to users. Open source is divided into two models, namely: 1) Open source based on community, a traditional open-source system and free as a whole. The system is suitable for organizations that will develop internal resources strongly, 2) Open source based on commercial support, An organization provides product services that although the code is free, the system is evaluated commercially. So the license is free, but the system must be adjusted to the needs.

Free software in the hypertext preprocessor (PHP) programming language used to handle MySQL administration through the World Wide Web (www) Network. Php myadmin supports a variety of MySQL operations, including (managing databases, tables, fields), relations (relations), indexes, users (users), permissions (permissions), and others). Managing 
a database with MySQL must be done by typing the appropriate command lines (command line) for each specific purpose.

Constraints experienced when making three-dimensional media that is the dimensions or scale used, the thickness of the paper used. initially using rice paper but had difficulty because it was difficult to fold the paper so that the paper turned into 500gr paper, cutting threedimensional media manually if excess cutting would cause the media to be unusable. For the development of software aided by website developers in its design and development.

At the development and implementation stage by conducting expert experts to determine the validity of three aspects namely material, media, and instructional design. The material was validated by three material experts namely 1 teacher and 1 school principal. The media were validated by three material experts namely 1 media expert and 1 teacher.

Instructional design validators provide suggestions and responses to the improvement of lesson plans. The suggestions given are as follows: (a) in learning activities must explain the activities of teachers and students; (b) learning objectives explain a, b, c, d; (c) Rubik assessment adjusted to the activities of students; (d) every learning activity must have a perception, motivation.

Evaluation results sent by students will be easily managed by the teacher. Each incoming file will be known to the time and who sent it. The results of expert reviews on barcode-based learning media can be seen in Table 1. Based on table 1. expert review was conducted with media experts, materials and instructional design. Validation was done twice. After analyzed, the average of 4.34 with the category was very valid. The advice was given to the expert review then improved by the researcher. Next prototype 1 was tested by involving three graders who had different abilities individually. At the end of the study, the researcher conducted an unstructured and open interview. Furthermore, prototype 2 will be tested from the limited test phase. This phase consists of eight class students who have characteristics similar to objective studies. Furthermore, students fill out questionnaires and provide comments and suggestions so that researchers can find out the advantages and disadvantages of barcode-based learning media.

At the end of the small group learning stage, students are also asked to fill in the questionnaire responses to prototype 2 that is being developed by researchers. Based on the results of students' questionnaire data showed an average of 3.8 and in the percentage of the average number of responses of students by $76 \%$ or $70 \%<$ an average of $\leq 85 \%$ means the response of positive students according to the criteria of positive student responses then the learning media developed by researchers is practical.

Table 1. Expert review results on barcode-based learning media

\begin{tabular}{llcl}
\hline & Expert & Average & Category \\
\hline Media experts & $1^{\text {st }}$ Validity & 4,76 & Very valid \\
\cline { 2 - 4 } & $2^{\text {nd }}$ Validity & 4,15 & Very valid \\
\hline Material experts & $1^{\text {st }}$ Validity & 4,25 & Very valid \\
\cline { 2 - 4 } & $2^{\text {nd }}$ Validity & 3,77 & Valid \\
& & & \\
\hline
\end{tabular}




\begin{tabular}{llll}
\hline & Expert & Average & Category \\
& & \\
\hline $\begin{array}{l}\text { Instructional design } \\
\text { experts }\end{array}$ & $1^{\text {st }}$ Validity & 4,74 & Very valid \\
\cline { 2 - 4 } & $2^{\text {nd }}$ Validity & 4,42 & Very valid \\
\hline
\end{tabular}

Student comments at the small group stage about the practicality of instructional media that need to be followed up with revisions are: 1) the initial screen display is given a background; 2) the resulting image resolution is too large; 3) writing is too tight. The field test phase aims to test the effectiveness of the learning outcomes of students on prototype 3 . At this stage of the field, the test is carried out for four meetings. The field test is conducted in August 2019. Learning activities are carried out in class VI A. Allocation of time is 2 x 35 minutes. The first meeting was held on August 5, 2019. Before the learning process was held, a preliminary test was held to measure the students' initial ability about the material with 10 multiple-choice questions. The second meeting was held on August 6, 2019. The third meeting was held on August 7, 2019. The fourth meeting was held on August 8, 2019. The fourth meeting was held posttest to see the effectiveness of learning outcomes. Post-test results obtained an average of 85.86 when compared with the KKM value, all students are finished. This shows that there is an increase in student learning outcomes using learning media

learning media also increases motivation so that learning outcomes reach KKM, this is in agreement with Sari's research (2014) from his research producing learning media that are valid, practical and have effects on learning outcomes.

\section{Conclusion}

Based on the results and discussion, the conclusions of the research development of a barcode-based multimedia three-dimensional multimedia learning media developed by the researcher are declared valid, practicality tested, and have effects on learning outcomes and activeness. The use of barcode-based multimedia three-dimensional learning media should use a smartphone that has a high screen resolution. Internet network is very necessary for product usage. This research can be useful for teachers, students, schools, and other researchers.

Acknowledgments. I would like to thank all the people who are important for this research. This study is far from perfect, but it is expected to be useful not only for researchers but also for readers. For this reason, constructive thought-full suggestions and critics are welcomed.

\section{References}

[1] Miarso, Y.: Menyemai benih teknologi pendidikan. Prenada Media kerjasama dengan PUSTEKOM, Indonesia (2004)

[2] Depdiknas: Panduan pelatihan guru kurikulum 2014. Badan Pengembangan Sumber Daya Manusia Pendidikan dan Kebudayaan, Indonesia (2014) 
[3] Amir, R.: Strategi \& desain pengembangan sistem pembelajaran. Prestasi Pustaka, Indonesia (2013)

[4] Tessmer, M.: Planning and conducting formative evaluations: Improving the quality of education and training. Kogan Page, UK (1998)

[5] Akker, J., Principles and Methods of Development Research. In T. N. Plomp, Design Approaches and Tools in Education and Training. Kluwer Academic Publisher, UK (1999) 